\title{
Genetically Transferred Central and Peripheral Immune Tolerance via Retroviral-Mediated Expression of Immunogenic Epitopes in Hematopoietic Progenitors or Peripheral B Lymphocytes
}

\author{
Elias T. Zambidis, Anupama Kurup, and David W. Scott \\ Department of Immunology, Holland Laboratory of the American Red \\ Cross, Rockville, Maryland, U.S.A. Department of Microbiology and \\ Immunology, and the Cancer Center, University of Rochester School \\ of Medicine and Dentistry, Rochester, New York, U.S.A.
}

\begin{abstract}
Background: Based on the hypothesis that IgGs are potent tolerogens and that immature lymphohematopoietic antigen-presenting cells (APC), and even mature peripheral B cells, may be effective APC for tolerance induction, we designed an immunoglobulin fusion protein retroviral expression vector to test the role of B cells in a novel gene therapy strategy for the transfer of immune tolerance.

Methods: An immunodominant epitope (residues 12-26 of the $\lambda$ repressor cI protein) was fused in frame to an IgG heavy chain in a retroviral vector, which was used to infect either bone marrow cells or activated peripheral B lymphocytes. These cells were transferred into syngeneic recipients, who were subsequently challenged with the 12-26 peptide in adjuvant.

Results: Bone marrow (BM) chimeras generated with retrovirally transduced bone marrow were shown to be
\end{abstract}

profoundly unresponsive to the $12-26$ peptide at both the humoral and cellular levels, but were competent to respond to an unrelated protein (lysozyme or PPD). Importantly, we also show that immunocompetent adult recipients infused with transduced mature, activated $B$ lymphocytes, are rendered unresponsive by this treatment. Surprisingly, lymphoid-deficient BM progenitors from syngeneic SCID donors could also be transduced to produce tolerogenic APC.

Conclusions: Our data suggest that activated B cells are sufficient to be effective tolerogenic APC in immunocompetent adult mice, but that nonlymphoid cells may also induce tolerance in reconstituted hosts. This approach for gene-transferred tolerogenesis has the potential to be maintained indefinitely, and it requires only knowledge of cDNA sequences of target antigens.

\section{INTRODUCTION}

A variety of experimental procedures have been described for the induction of antigen-specific tolerance in neonates and adults (1-3). In the immunocompetent adult, however, tolerance in-

Address correspondence and reprint requests to David W. Scott, Holland Laboratory of the American Red Cross, Department of Immunology, 15601 Crabbs Branch Way, Rockville, MD 20855, U.S.A. Phone: 301-517-0335; Fax: 301-517-0344; E-mail: scottd@hlsun.red-cross.org

Elias T. Zambidis's present address: Box 353, University of Rochester School of Medicine and Dentistry, 601 Elmwood Avenue, Rochester, NY 14642, U.S.A. duction has been generally more difficult. Tolerance to foreign transplantation antigens or viral cytotoxic T lymphocyte (CTL) epitopes, for example, has previously been shown to be most effective primarily in models where hematopoietic or lymphoid ablation is followed by reconstitution with antigen-expressing bone marrow (BM)-derived antigen-presenting cells (APC) (4-8). For autoimmune disease, a variety of studies have focused on the acquired induction of tolerance to autoantigens to prevent and/or ameliorate disease. For example, in murine models for multiple sclerosis and diabetes, prevention 
of disease has been successfully accomplished with thymic, oral, and intravenous, high-dose administration of target autoantigens $(9-11)$.

A strategy for the induction of clinically relevant tolerance can be indirectly derived from the original experiments demonstrating tolerance induction to foreign major histocompatibility complex (MHC) antigens via the injection of allogeneic hematopoietic cells into neonates (1). In adults, however, attempts to induce tolerance to foreign grafts by injecting accessory celldepleted splenocytes $(12,13)$ or syngeneic transfected cells (14) has met with limited success. The advent of efficient methods for gene transfer into hematopoietic cells may in theory enable the expression of foreign antigens for the induction of tolerance via pathways similarly used for tolerance induction to naturally expressed determinants (e.g., MHC, Mls antigens) in bone marrow chimeras (15-18). Since such approaches have usually required some degree of myeloablation, a more desirable approach would be to adoptively transfer genetically modified peripheral APC (19), which engraft more efficiently in the unconditioned host. An excellent candidate for such a strategy would be the peripheral B lymphocyte that has been described to possess immune-modulating characteristics. Previous studies have shown that, in some circumstances, antigen-presenting B cells are capable of inducing peripheral tolerance in mature, naive $\mathrm{T}$ cells in vivo (20-23), or even previously activated $\mathrm{T}$ cell clones in vitro (24).

To test the potential for gene-transferring model target antigens into autologous APC, as well as the role of $B$ cells in this process for the induction of specific immune tolerance, we created a recombinant, replication-defective retroviral vector for the expression of a foreign class II MHC-restricted immunodominant epitope. Our model determinant, residues $12-26$ from $\mathrm{cI} \lambda$ repressor protein (pl-102), contains both a $\mathrm{T}$ and $B$ cell epitope $(25,26)$ and has been fused at the $\mathrm{N}$ terminus of a murine IgG $\mathrm{H}$ chain. Engineered Ig expressing heterologous epitopes has been described for the potentiation of peptidespecific immunity (27), and we have recently expanded this approach by describing the tolerogenic properties of a soluble engineered 12-26IgG fusion protein (28). Here we show that bone marrow chimeras generated with retrovirally transduced marrow or even immunocompetent adult recipients infused with transduced mature, activated B lymphocytes are highly unresponsive to the peptide at both the humoral and cellular levels. The genetic transfer and expression of immunogenic epitopes or whole complex antigens by appropriate "nonprofessional" APC may have great utility for the specific elimination of undesirable immunity associated with autoimmune states $(9-11)$, recombinant clotting factor administration (29), and gene therapy protocols $(30,31)$.

\section{MATERIALS AND METHODS}

\section{Replication-Defective Retroviral Vectors and Gene-Transfer Protocols}

The 12-26-IgG $\mathrm{H}$ chain cDNA was derived by reverse transcriptase-polymerase chain reaction (RT-PCR) from J558L myeloma cells, transfected with the rearranged genomic construct (28), and subcloned into retroviral vector MBAE (32) containing long terminal repeats (LTR), $\psi^{+}$packaging signals, a neomycin resistance gene, and cloned human $\beta$-actin promoter sequences. PCR primers encoded $5^{\prime}$ Ig $\mathrm{H}$ chain leader and $3^{\prime} \mathrm{IgG}_{1}$ as well as Sal $\mathrm{I}$ restriction site sequences: " $\mathrm{V}_{\mathrm{H}}$ 5' primer": TGG ACT AAG TCG ACA CCA TGG GAT GGA GC; "Gl 3' primer": TCG GAA GGG TCG ACG GAT CAT TTA CCA GGA GA. A single batch of the $\psi$-2 packaging line (F6P) was prepared with recombinant plasmid MBAE.BAK and assayed for helper virus via horizontal spread of neomycin resistance with NIH 3T3 cells. Each aliquot was assayed before use and found to contain $\sim 10^{5}-10^{6}$ (usually $\geq 5 \times 10^{5}$ ) neomycin-resistant NIH 3T3 CFU/ml. Ecotropic F6P was prepared by "ping-pong" amplification using amphotropic line PA317. Producer lines were stored in liquid nitrogen and freshly thawed cells were re-titered and utilized for each individual experiment.

B cell lines (CH31, A20, J558L, and NS-1; all from ATCC, Rockville, MD) were transduced with recombinant retrovirus via co-culture with adherent F6P cells for $24-48 \mathrm{hr}$ in the presence of $6 \mu \mathrm{g} / \mathrm{ml}$ polybrene (Sigma). Cells in suspension were washed and recultured in $1 \mathrm{mg} / \mathrm{ml}$ G418 for selection of stable transductants prior to genomic Southern blot, RT-PCR, ELISA, or antigen-presentation studies. Infection of BM progenitors and quantitation of G418-resistant colony-forming cells (CFC) have been described elsewhere (33-35). BM was harvested from femurs and tibiae of 6- to 8-week-old BALB/c donors injected IV with $150 \mathrm{mg} / \mathrm{kg} 5$-fluorouracil 3-4 days previously. Erythrocyte-depleted BM 
was co-cultured $\left(5 \times 10^{6} / \mathrm{ml}\right)$ with irradiated (2,000 rads) F6P or $\psi$-2 parental cells (mock transduction). Ten-ml cultures in complete RPMI 1640 with $15 \%$ FCS were incubated at $37^{\circ} \mathrm{C}, 5 \%$ $\mathrm{CO}_{2}$ for $48 \mathrm{hr}$, and they included $200 \mathrm{U} / \mathrm{ml}$ each of IL-3, IL-6, and IL-7 (Genzyme). Four $\mu \mathrm{g} / \mathrm{ml}$ polybrene was added to co-culture during the last $24 \mathrm{hr}$ of infection.

Splenic B cells were similarly infected in vitro via co-culture with viral-producing $\mathrm{F} 6 \mathrm{P}$ or parental $\psi-2$ (mock transduction). Peripheral B cells were purified with anti-T cell antibody cocktail plus complement and Percoll density gradients $(60-70 \%$ layers $)$. Purified B cells were prestimulated with $50 \mu \mathrm{g} / \mathrm{ml}$ bacterial lipopolysaccharide (LPS, E. coli 055:B5, Sigma) overnight, and recultured $\left(3 \times 10^{6} / \mathrm{ml}, 5 \mathrm{ml}\right.$ cultures $)$ with irradiated F6P in the presence of $4 \mu \mathrm{g} / \mathrm{ml}$ polybrene and $50 \mu \mathrm{g} / \mathrm{ml}$ LPS for an additional $24 \mathrm{hr}$.

\section{Tolerance Induction and Measurement of Peptide-specific Cellular and Humoral Immunity}

Adult (6- to 8-week-old) $\mathrm{BALB} / \mathrm{c}$ recipients (Jackson Labs) were sublethally irradiated (200600 rads total body irradiation) and injected intravenously (lateral tail vein) with 1-2 $\times 10^{6}$ gene-transferred or mock-transduced BM progenitor cells. Unconditioned, normal BALB/c were similarly injected with $>1 \times 10^{7}$ genetransferred LPS blasts. All cells were washed extensively in serum-free medium and injected IV in a volume of $500 \mu \mathrm{l}$. Recipients were analyzed for expression of recombinant retrovirus as well as immune tolerance to 12-26 peptide 2-12 weeks later. Tolerized recipients were immunized for cellular or humoral immune responses essentially as described elsewhere $(25,28)$. Animals were subcutaneously injected at the base of the tail with $50 \mu \mathrm{g}$ synthetic $12-26$ peptide emulsified 1:1 CFA. In some experiments, animals were also injected with $10 \mu \mathrm{g}$ hen egg lysozyme (HEL) in CFA, intraperitoneally (IP) as a specificity control. Two weeks later, mice received an additional IP boost of $50 \mu \mathrm{g}$ peptide and $10 \mu \mathrm{g}$ HEL in saline. Antibody titers were determined from serum bleeds 8 days after secondary boosts. Splenic memory $\mathrm{T}$ cell responses were measured in vitro 6-8 weeks following these secondary challenges by reculturing (in triplicate) purified $\mathrm{T}$ cells $\left(3 \times 10^{6} / \mathrm{ml}\right)$ with irradiated $(2,500$ rads $)$ BALB/c splenocytes $\left(1 \times 10^{6} / \mathrm{ml}\right)$ and dilutions of synthetic peptide. Serum peptide-specific or
HEL-specific IgG responses were determined by ELISA by coating plates with $50 \mu \mathrm{g} / \mathrm{ml}$ synthetic peptide or $5 \mu \mathrm{g} / \mathrm{ml} \mathrm{HEL}$ as described elsewhere $(25,28)$. Cellular responses from draining popliteal and inguinal LN cells were assayed 9 days after immunizing mice in the hind footpads with $20 \mu \mathrm{g}$ peptide emulsified in CFA. On Day 3, (triplicate) cultures were pulsed with $1 \mu \mathrm{Ci} /$ well of $\left[{ }^{3} \mathrm{H}\right]$ thymidine and incubated an additional 14-20 hr for the determination of proliferative responses. Cells were then harvested on glass fiber filters and incorporated ${ }^{3} \mathrm{H}$ was detected using a direct $\beta$-counter (Packard, Matrix 9600). IL-2 and IL-4 cytokine production was quantitated by CTL line (CTLL) and CT.4S bioassays, respectively, using serial dilutions of LN or splenic culture supernatants and recombinant cytokine standards (Genzyme). Dilutions of antiIL-2 mAb S4B6 and anti-IL-4 mAb 11Bll (ATCC) were included to establish specificity. Murine IFN- $\gamma$ was determined with a commercially available ELISA kit (Intertest- $\gamma$, Genzyme).

\section{RT-PCR and Immunologic Methods}

Detection of 12-26-IgG transcripts in transduced cell lines or hematopoietic tissue from BM-injected mice was performed with a 12-26 sequence RNA-PCR assay. Primers were designed to amplify $5^{\prime}$ immunoglobulin leader sequence $\left(\mathrm{V}_{\mathrm{H}} 5^{\prime}\right.$ primer, as above) and $3^{\prime} 12-26$ sequence, ( $3^{\prime}$ pep primer): GGC AAC AGA AGC TTT CAC TTC TTC TTC TCG TAT. Briefly, $1-5 \mu \mathrm{g}$ of total RNA from various tissue was reverse transcribed ( 2 rounds) with AMV reverse transcriptase, dNTPs, and oligo dT and random hexamer primers (Invitrogen cDNA cycle kit) at $42^{\circ} \mathrm{C}$. The resultant cDNA was amplified with $5^{\prime}$ and $3^{\prime}$ primers described above and Taq polymerase (Perkin-Elmer, Cetus). PCR conditions were 45 sec at $93^{\circ} \mathrm{C}, 2 \mathrm{~min}$ at $47^{\circ} \mathrm{C}$, and $2 \mathrm{~min}$ at $72^{\circ} \mathrm{C}$ for 35-40 cycles. Amplified DNA products were loaded (1/10-1/100 sample) onto $2 \%$ agarose/TBE gels and subsequently transferred onto nylon membranes for Southern blot analysis. 12-26 sequences were confirmed in RTPCR-amplified DNA samples with a $\gamma-{ }^{32} \mathrm{P}$-labeled oligonucleotide (oligo Ig-one) encoding 12-26 but which does not overlap with the $3^{\prime}$ PCR primer: TGA TCT ACT GCA GCT GGA GGA CGC GCG GCG G. Tissue RNA samples were compared via $\beta$-actin RT-PCR using commercially available primers (Stratagene).

12-26-IgG $\mathrm{H}$ chain protein was detected in culture supernatants of transduced cell lines or in 
sera of mice injected with gene-transferred cells, via its ability to bind to the NIP (5-iodo-4-hydroxy-3-nitrophenylacetyl) hapten using a modified NIP-binding ELISA (36). Briefly, dilutions of culture supernatants or sera were incubated on ELISA plates coated with NIP-gelatin conjugate $(10 \mu \mathrm{g} / \mathrm{ml})$ and subsequently probed with goat anti-mouse $\operatorname{IgG}_{1}$-AP as a secondary reagent. Standard curves with affinity-purified 12-26-IgG from supernatants of transfected J558L were used for quantitation.

\section{RESULTS AND DISCUSSION}

A recombinant retroviral vector (32) was modified by inserting a PCR-derived cDNA encoding the 12-26-IgG $\mathrm{H}$ chain sequence (Fig. 1A), and an ecotropic packaging line (F6P) was generated for the in vitro infection of cell lines and hematopoietic tissue via co-culture methods (33-35). For initial studies, a variety of B cell lines at various stages of differentiation were transduced, including $\mathrm{CH} 31$ (immature), A20 (mature, activated), NS-1, and J558L (plasmacytomas). Intact proviral integration in transduced G418-resistant A20 cells could be verified by genomic Southern blotting using a DNA probe specific for $12-26$ sequence (Fig. 1A). More importantly, 12-26IgG heavy $(H)$ chain can assemble with endogenous light chains in transduced B cell lines, which can be expressed as a membrane-surface protein (Fig. 1B) or secreted into cultured supernatants $(50-80 \mathrm{ng} / \mathrm{ml})$ in $\mathrm{NS}-1$ and $\mathrm{J} 558 \mathrm{~L}$ myelomas. Immunoprecipitation of secreted 1226-IgG and immunoblot analysis with a peptidespecific monoclonal antibody (B3.11) could directly demonstrate the expression of 12-26 peptide (Fig. 1C).

Although retrovirally synthesized gene products are expected to give rise primarily to processed peptides presented by MHC class I molecules, endogenously derived peptides can also be routed to endocytic class II MHC compartments in some cases (37-39). Our initial hypothesis was that such a pathway would be enhanced for retrovirally encoded 12-26-IgG $\mathrm{H}$ chain due to the efficient nature of the immunoglobulin secretory pathway in targeting the endosomal compartment. To test for direct presentation of our model immunodominant class II-restricted peptide, we tested the ability of 12-26-IgG-transduced A20 cells to directly activate peptide-specific $\mathrm{T}$ cell hybrid 9C127, which recognizes $12-26$ in the context of I-A ${ }^{d}(26)$. Efficient presentation of endogenously synthesized peptide could be demonstrated, and this effect could be blocked with antibodies to CD4 or class II MHC molecules (Fig. 1E). These studies predict that, in vivo, 12-26 peptide has the potential to be recognized directly by $\mathrm{T}$ cells from a variety of gene-transferred APC (lymphoid and nonlymphoid). Additionally, synthesis, light chain assembly, and secretion of 12-26-IgG $\mathrm{H}$ chain by $\mathrm{B}$ cells can potentially result in re-presentation by endogenous host APC.

Our next experiments tested the potential of genetically modified BM to specifically tolerize a regenerating immune repertoire (central tolerance induction). We therefore developed bone marrow chimeras in sublethally irradiated (200600 rads) $\mathrm{BALB} / \mathrm{c}$ by infusing 5-fluorouracil (FU)-pretreated donor BM that had been cocultured with F6P. This protocol gives rise to newly developing lymphocytes and APC (lymphoid and nonlymphoid) that are derived from the transplanted $\mathrm{BM}$ progenitors expressing 12 26-IgG heavy chain, as well as radioresistant APC from the host. Mice were immunized 4-12 weeks post-infusion and 12-26 peptide-specific immune responses were measured $(25,28)$. Analysis of hematopoietic tissue collected at sacrifice times using a peptide sequence-specific RT-PCR assay indicated that transcripts were expressed consistently and reproducibly in the bone marrow of all gene-transferred recipients, although variably in the thymus or spleen (a subset of these are illustrated in Fig. 1D). Furthermore, a very sensitive NIP-binding $\operatorname{IgG}_{1}$ ELISA was developed (36) that could detect secreted 12-26-IgG in the serum as a result of pairing with endogenous $\lambda$ light chains specifically by stem cell-derived B lymphocytes. Although this assay detects only a fraction of $\mathrm{H}$ chain secreted by B cells ( $\lambda$ light chain-paired), expression could be detected in approximately one-third of all gene-transferred BM recipients (see also Table 1). Despite these variable serum expression patterns, dramatic and reproducible peptide-specific tolerance was observed in all recipients analyzed (22/22 total) of 12-26-expressing progenitor cells, which was demonstrated following immunization with synthetic peptide emulsified in complete Freund's adjuvant (CFA). Specific $\mathrm{T}$ cell proliferative and cytokine responses of draining lymph node (LN) cells were significantly diminished (Fig. 2), as were antipeptide antibody titers following priming and a secondary antigenic boost (Fig. 3).

Since our BM transduction protocol targets 
A

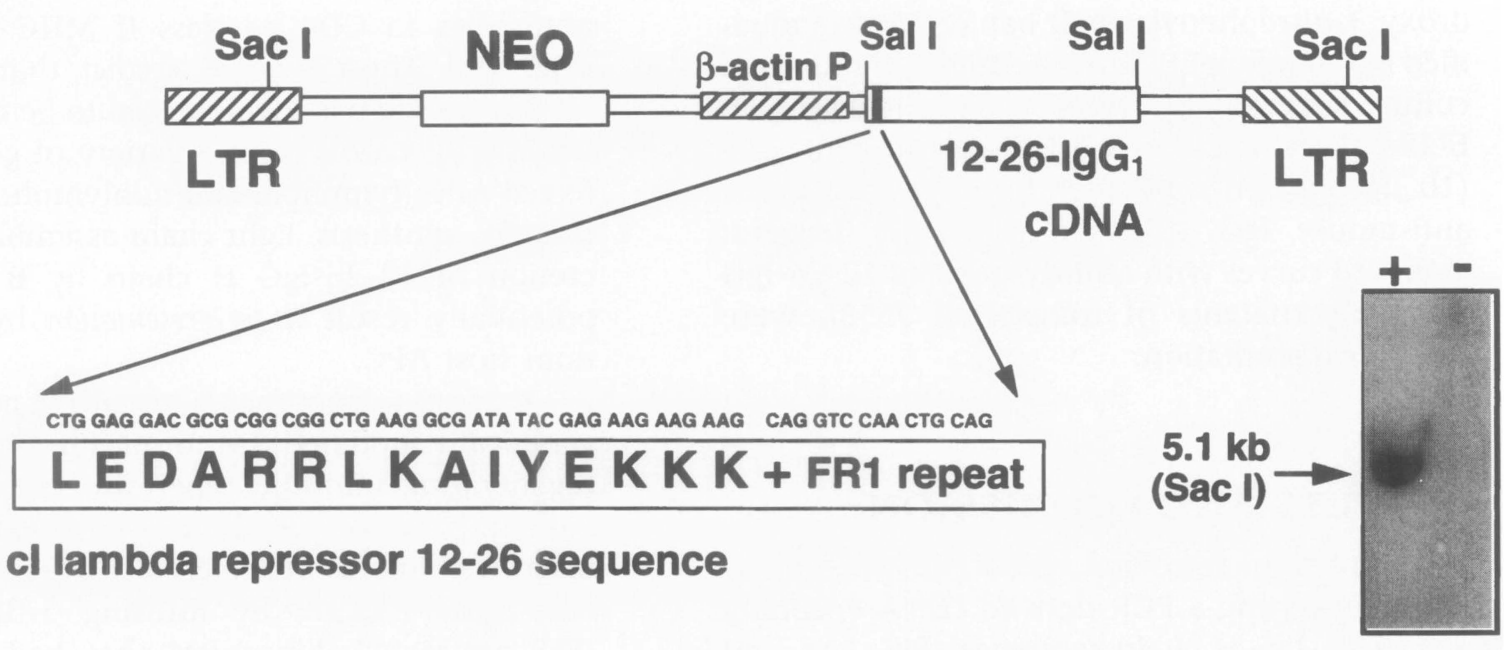

B

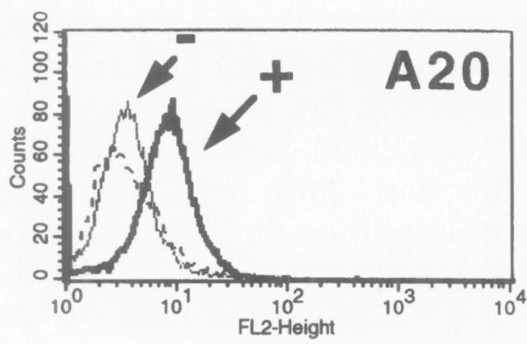

C

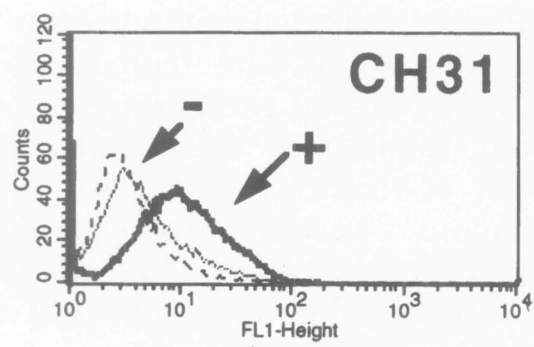

D

BM recipient 123412312

gene transfer -+++-++-+-+

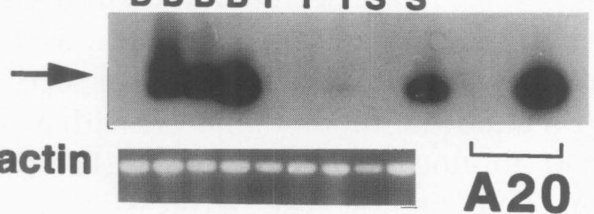

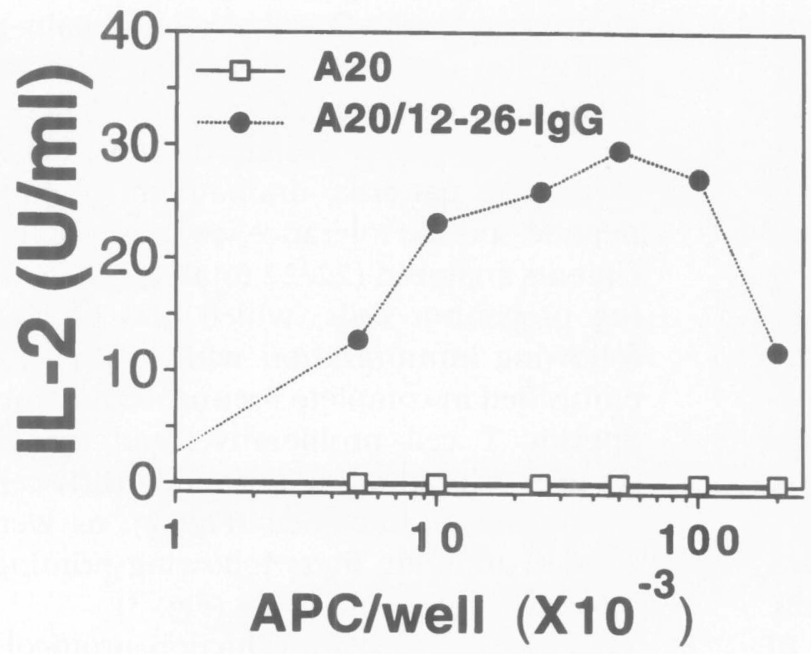

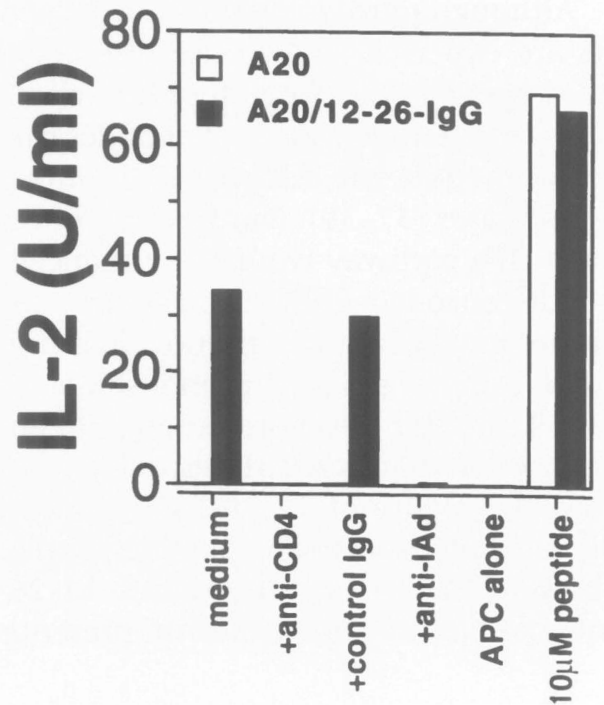


viral integration into early hematopoietic progenitors, and both the $5^{\prime}$ viral LTR and $\beta$-actin promoters are lineage-nonspecific, a variety of differentiated APC types may directly tolerize developing lymphocytes. We hypothesized that transduced, stem cell-derived nonlymphoid APC (e.g., monocytes, macrophages, and dendritic cells), which cannot synthesize light chains, and thus cannot secrete peptide-IgG, may also play a critical role in directly presenting transgenic peptide to developing lymphocytes. To test this hypothesis, we gene-transferred syngeneic BM

FIG. 1. B cell expression, epitope recognition, and direct antigenic presentation of retrovirally synthesized peptide-IgG

(A) Structure and proviral integration of murine Moloney leukemia retroviral construct MBAE.BAK. Ten micrograms of genomic DNA from transduced, G418-resistant (+) or control (-) A20 cells was digested with Sac I, fractionated on $0.8 \%$ agarose, Southern-blotted, and probed with ${ }^{32} \mathrm{P}$-labeled DNA probe containing three tandem copies of $12-26 \mathrm{se}$ quence. Sac I digestion releases an $\sim 5.1 \mathrm{~kb}$ proviral genome. (B) Surface IgGl expression on transduced, G418-resistant $(+)$ or control (-) $\mathrm{A} 20\left(\mathrm{sIgG}_{2 \mathrm{~b}}{ }^{+}\right)$or $\mathrm{CH} 3 \mathrm{l}\left(\mathrm{sIgM}^{+}\right) \mathrm{B}$ cell lines. Cells were probed with either goat anti-mouse IgGl (adsorbed)-PE (Caltag) or biotinylated anti-mouse $\operatorname{IgG}_{1}{ }^{\mathrm{b}}$ (Pharmingen) plus streptavidin-FITC. Dashed lines show isotypematched or secondary reagent controls. (C) Detection of 12-26 peptide on secreted Ig-peptide $\mathrm{H}$ chain. Culture supernatants from transduced, G418-resistant (+) or control (-) J558L myelomas were immunoprecipitated with either goat anti-mouse IgG 1 agarose or NIP-sepharose beads. Samples were resolved on $10 \%$ SDS-PAGE, transferred onto nitrocellulose, blocked with $2 \% \mathrm{BSA}$, and probed with biotinylated mAb B3.1 1 (anti-12-26 epitope) plus streptavidin-AP as a secondary reagent. (D) Tissue expression of 12-26 mRNA in long-term $(\sim 3$ months) recipients of gene-transferred $(+)$ or mocktransduced (-) BM progenitors. RNA from bone marrow (B), thymus (T), or spleen (S) was assayed by 12-26 sequence RT-PCR (25). One-tenth of each PCR reaction (except for A20 controls: 1/100th) was Southern blotted and probed with a noncomplementary ${ }^{32} \mathrm{P}$-labeled 12-26-specific oligonucleotide. For simplicity, only a subset of representative tissues are shown. (E) Direct presentation of endogenously synthesized peptide to 12-26-specific T cell hybrid, 9C127. Microcultures $(200 \mu \mathrm{l})$ of transduced or control A20 cells were plated at various dilutions with $2 \times 10^{4} 9 \mathrm{Cl} 27$ per well for $24 \mathrm{hr}$. T cell stimulation in the absence or presence of various blocking antibodies (lower right) was assayed via CTLL assay with serially diluted supernatants and recombinant IL-2 standards. from severe combined immunodeficiency (SCID) mice to analyze the tolerogenic potential of myeloid APC. Although hematopoietic tissue from SCID mice can be shown to be defective in developing mature lymphoid cells, myeloid lineage APC function remains intact (40). 5-FU-pretreated SCID or normal BALB/C donor BM was co-cultured with $\mathrm{F} 6 \mathrm{P}$, and stem cells were injected into sublethally irradiated normal BALB/C recipients (normal lymphocytes regenerate only from host stem cells in the case of SCID BM recipients). BM chimeras were rested for 2 months and subsequently immunized with 12-26 peptide for the measurement of humoral immune tolerance. Interestingly, peptide-specific tolerance induction was found to be comparable between recipients of either normal or lymphoid-deficient BM whereas mock-transduced BM recipients maintained high-titer humoral immunity (Fig. 3). Analysis of G418-resistant hematopoietic colony-forming cells from recipients of transduced normal or SCID BM showed that the proportion of BM-derived myeloid stem cells expressing our construct was similar $(1-5 \%$, Table 1).

Although antigenic shedding from 12-26IgG heavy chain-"expressing" SCID myeloid cells and subsequent lymphoid APC re-presentation cannot be ruled out, these experiments strongly suggest that in addition to tolerogenesis by lymphoid APC (8-12), as well as secreted fusion IgG, transduced myeloid BM-derived APC can also share this potential, at least in the reconstituted recipient. This is important because engineered tolerogenic peptide may be "expressed" (processed) in professional, but nonactivated, APC that may would be capable of inducing tolerance in unprimed, developing $\mathrm{T}$ cells (cf. ref. 22). This result may explain the consistent tolerance observed in all recipients of normal transduced BM, regardless of detectable serum production of 1226-IgG (B-lymphocyte-derived transgene). Thus, multiple pathways of tolerogenesis may be occurring in these hosts.

Although efficient induction of tolerance in developing lymphocytes could be readily and reproducibly accomplished with genetically modified BM, a more favorable approach for genetransferred tolerogenesis would be to induce peptide-specific peripheral tolerance in the mature immune repertoire, without requirement for myeloablation. Since potent tolerance in normal, immune-competent recipients can be induced via injection of large numbers of mature $B$ lymphocytes expressing H-Y (22) or Mls antigens 
TABLE 1. Expression of serum 12-26-IgG and G418-resistant BM progenitors in genetically tolerized BALB/c mice

\begin{tabular}{|c|c|c|c|c|}
\hline Mice & $\begin{array}{l}\text { BM Gene } \\
\text { Transfer }\end{array}$ & $\begin{array}{l}\text { Serum NIP-binding } \\
\text { IgG } 1, \text { ng/ml (time*) }\end{array}$ & $\begin{array}{c}\% \mathbf{G} 418^{\mathrm{R}} \\
\mathrm{CFC} / \mathrm{ml}\end{array}$ & $\begin{array}{l}\text { Tolerance } \\
\text { Induction }\end{array}$ \\
\hline \multicolumn{5}{|c|}{ Experiment 1} \\
\hline $1,2,3$ & $-* *$ & $<0.1(3,7$ weeks $)$ & $\mathrm{NT} * * *$ & - \\
\hline 4 & + & $20,2(3,7$ weeks $)$ & NT & + \\
\hline 5 & + & $<0.1,20(3,7$ weeks $)$ & NT & $+1-$ \\
\hline 6 & + & $60,2(3,7$ weeks $)$ & NT & + \\
\hline 7 & + & $120,20(3,7$ weeks $)$ & NT & + \\
\hline 8 & + & $10,<0.1(3,7$ weeks $)$ & NT & + \\
\hline \multicolumn{5}{|c|}{ Experiment 2} \\
\hline $9,10,11$ & - & $<0.1$ (6 weeks) & NT & - \\
\hline 12 & + & 135 (6 weeks) & NT & + \\
\hline 13 & + & <0.1 (6 weeks) & NT & + \\
\hline 14 & + & 15 (6 weeks) & NT & + \\
\hline 15 & + & $<0.1$ (6 weeks) & NT & + \\
\hline 16 & + & $<0.1$ (6 weeks) & NT & + \\
\hline \multicolumn{5}{|c|}{ Experiment 3} \\
\hline $17,18,19$ & - & $<0.1$ ( 3 weeks) & NT & - \\
\hline 20 & + & $<0.1$ ( 3 weeks) & NT & + \\
\hline 21 & + & 30 (3 weeks) & NT & + \\
\hline 22 & + & $<0.1$ ( 3 weeks) & NT & + \\
\hline \multicolumn{5}{|c|}{ Experiment 4} \\
\hline $23,24,25$ & - & NT & 0 (11 weeks) & - \\
\hline 26 & + & NT & 2.2 (11 weeks) & + \\
\hline 27 & + & NT & 2.8 (11 weeks) & + \\
\hline 28 & + & NT & 2.8 (11 weeks) & + \\
\hline 29 & $+($ SCID $)$ & NT & 5.4 (11 weeks) & + \\
\hline 30 & $+($ SCID $)$ & NT & 1.3 (11 weeks) & + \\
\hline 31 & $+($ SCID) & NT & 4.7 (11 weeks) & + \\
\hline
\end{tabular}

Recipients of F6P or mock-infected 5-FU bone marrow (BM) progenitors were assayed for transgene expression in serum or BM at indicated time points. BM CFC were assayed at sacrifice time in $0.3 \%$ semisolid agar cultures in long-term recipients. BM cultures of $10 \%$ well in complete IMDM included $15 \%$ FCS, $200 \mathrm{U} / \mathrm{ml} \mathrm{IL-3,} \mathrm{and} 10 \%$ ORIGEN conditioned medium (GIBCO, BRL)

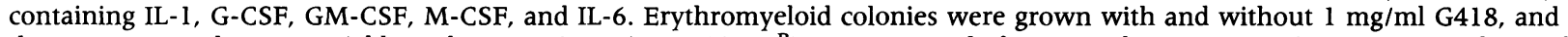
the percentages that were viable and neomycin-resistant $\left(G 418^{R}\right)$ were counted after $7-10$ days. BM recipients were conditioned with either 200 rads (Experiment 1) or 600 rads (Experiments 2-4). Detailed experimental results for Experiments 1 and 4 are presented in Fig. 3A and B, respectively; results for Experiments 2 and 3 are not presented. *Time after transfer; ${ }^{* \star}+$, yes, - , no; $* * \star N T$, not tested.

(20), we wished to similarly test the tolerogenicity of peptide-IgG-transduced peripheral B cells. Our protocol consisted of stimulating Percoll gradient-purified splenic B cells to proliferate with bacterial lipopolysaccharide (LPS), brief co-culture with F6P, and subsequent IV injection into normal, immunocompetent BALB/c. This treatment resulted in an efficient suppression of pep- tide-specific humoral immunity comparable to that observed for bone marrow chimera experiments. Splenic memory $\mathrm{T}$ cell responses were measured approximately 3 months after immunization in these tolerized animals, and revealed a potent IL- 2 and IL- 4 cytokine reduction, which is indicative of effective tolerization in both Thl and Th2 compartments, respectively (Fig. 4A). 


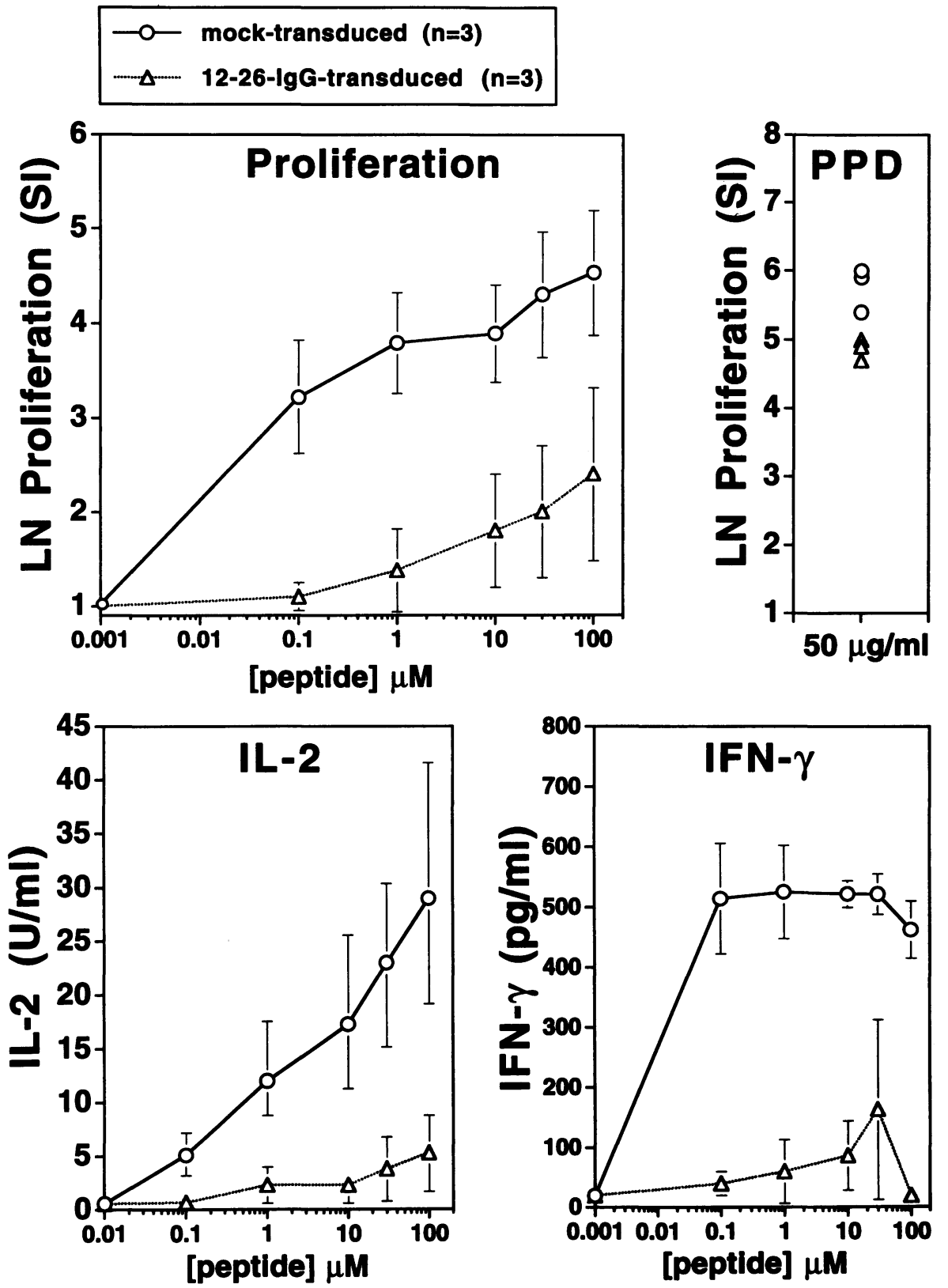

FIG. 2. Induction of peptide-specific cellular immune tolerance in adult bone marrow chimeras infused with peptide-Igexpressing progenitor cells

$\mathrm{BALB} / \mathrm{c}$ mice were sublethally irradiated (600 rads) and injected IV with 1-2 $\times$ $10^{6}$ gene-modified or mocktransduced BM. Recipients were immunized with peptide in CFA 2 months postinfusion and draining $\mathrm{LN}$ cells were restimulated in vitro with dilutions of synthetic peptide and 25-50 $\mu \mathrm{g} / \mathrm{ml}$ purified protein derivative (PPD, Connaught) in CRPMI 1640 with $0.5 \%$ heatinactivated autologous serum. Stimulation indices (SI) represent ratios of proliferation to medium alone backgrounds $(5,609 \pm 2,271$ cpm). IL-2 and IFN- $\gamma$ were quantitated by CTLL and ELISA assays, respectively (24). Additional experiments also revealed a diminution of peptide-specific IL-4 release in $\mathrm{LN}$ of tolerized recipients (data not shown). Error bars signify standard error of the mean for 3 individual mice per group. This experiment was done at least twice with 3-4 mice per group with similar results.
Furthermore, G418-resistant hybridomas could be generated from LPS-activated spleens of these tolerized mice by fusion with A20 lymphoma cells using polyethylene glycol (PEG). These hybrids were capable of stimulating peptide-specific $9 \mathrm{C} 127 \mathrm{~T}$ cells directly (Fig. 4B), thus displaying that gene-transferred peripheral $\mathrm{B}$ cells are capable of persisting and presenting 12-26-IgG selfantigen for long periods of time for the induction and maintenance of peptide-specific tolerance. Whether this is due to tolerogenic B cell antigenic presentation or secretion of the fusion IgG in these recipients is not known, although both are likely. Such long-term persistence $(>3-6$ months) is in agreement with similar results for injection of normal (41) as well as genetically modified, LPS-activated peripheral B cells (19).

These model studies outline a novel, efficient strategy by which foreign immunogens and target autoantigens may be delivered to the immune system in a tolerogenic manner as a soluble Ig fusion protein expressed in hematopoietic tissue. Genetic transfer of antigenic sequences either into a multipotential stem cell or in a 

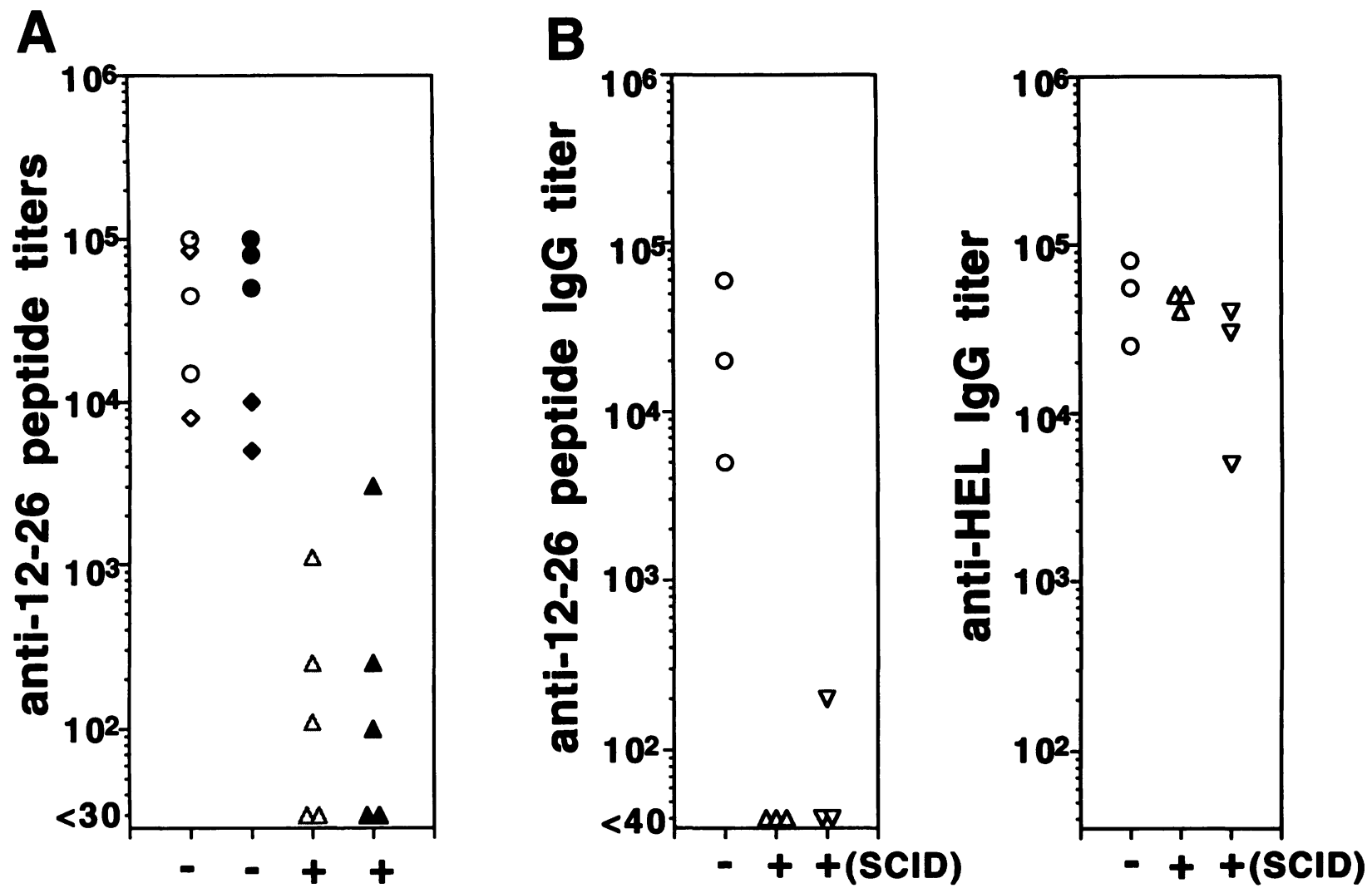

FIG. 3. Induction of peptide-specific humoral immune tolerance in adult bone marrow chimeras infused with peptide-Ig-expressing progenitor cells

$\mathrm{BALB} / \mathrm{c}$ mice were sublethally irradiated with either (A) 200 rads, or (B) 600 rads and infused with $1-2 \times 10^{6}$ gene-transferred $(+$, triangles) or mock-transduced $(-$, circles) BM cells. Mice were primed and boosted for humoral responses either (A) 1 month or (B) 2 months post-infusion with synthetic 12-26 peptide, and with HEL as a specificity control. Nonmanipulated, immunized BALB/c always produced titers similar to recipients infused with mock-transduced BM cells (A, diamonds). Both total peptide-specific IgG (open symbols), or the main isotype IgGl (closed symbols) were diminished in all experiments (both shown only for A). Normal BALB/c recipients in (B) received either 5-FU-pretreated normal BALB/c BM or SCID/BALB/c BM cells. Flow cytometry analysis at sacrifice time in (B) revealed comparable levels of $\mathrm{CD}^{+}$and $\mathrm{Ig}^{+}$splenocytes in normal BALB/C reconstituted with either normal or SCID BM: $\left(\mathrm{CD}^{+}: 18-25 \% ; \mathrm{Ig}^{+}: 40-65 \%\right)$. All experiments have been done at least twice with 3-5 mice per group with similar results.

peripheral B cell may permit the induction, and more importantly, the long-term maintenance of specific immune self-tolerance in the autologous host. Our choice of a model immunodominant peptide capable of inducing both high-titer IgG antibody responses (Th2-mediated), as well as vigorous cellular (Th1-mediated) responses underscores the versatility of our method. Although gene transfer of BM with class I MHC-restricted CTL epitopes efficiently induces tolerance (42), our approach of fusing antigenic sequence to immunoglobulin molecules likely allows for the efficient presentation of a retrovirally synthesized class II MHC-restricted epitope by both lymphoid and nonlymphoid cells, although we have not yet formally compared a membrane and secretable form of the fusion IgG. Furthermore, in addition to effective Th tolerance induction, the bivalent nature of the secreted form of the Ig-epitope molecule can also independently mediate effective peptide-specific $B$ cell tolerance, most likely via Fc-mediated antibody feedback mechanisms (28). Thus, the potency of tolerance induction in our model system may be due to the efficiency of very low level expression of this unique tolerogen and may follow multiple pathways.

The use of tolerogenic peptide-Ig constructs 


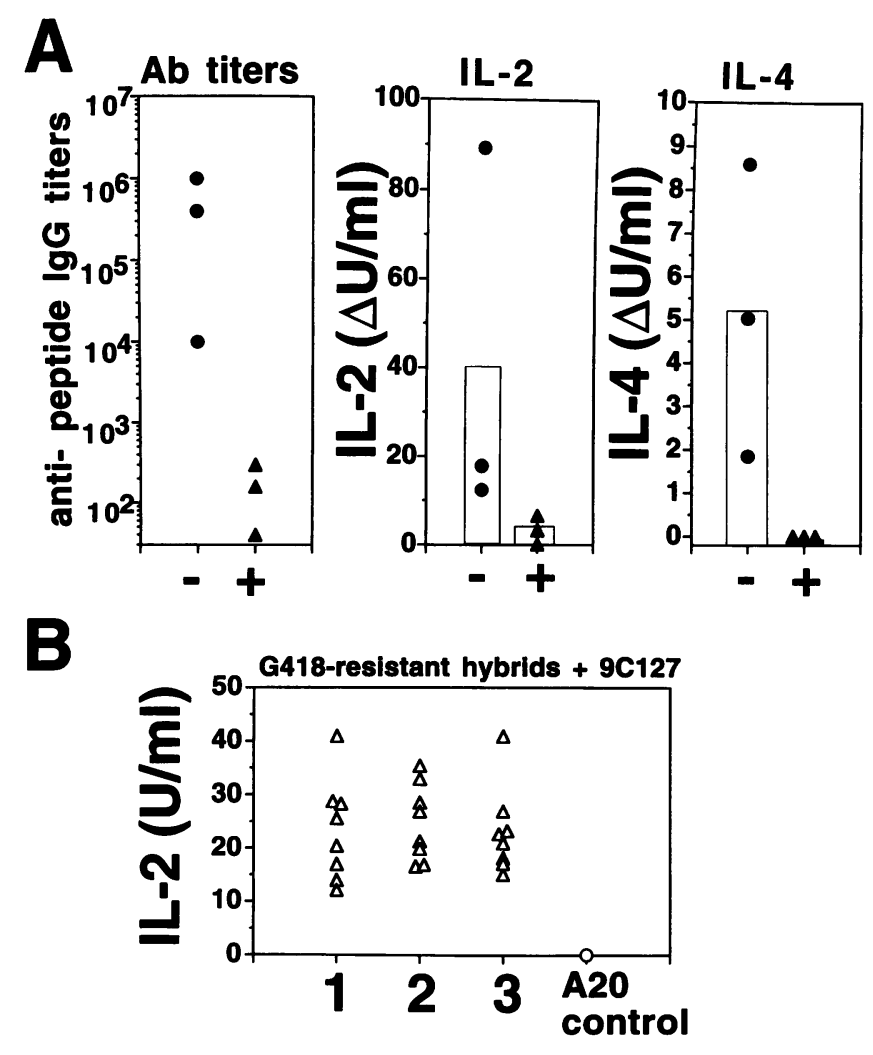

FIG. 4. Peripheral tolerance induction in immunocompetent adults with gene-transferred peripheral B cells expressing engineered peptide-Ig

(A) Humoral and cellular tolerance induction. Nonirradiated BALB/c were injected with $>1 \times 10^{7}$ LPS blasts co-cultured with retrovirus-producing F6P (+) or mock-transducing $\psi$-2 $(-)$. One week later, mice were primed and boosted for humoral responses as before, and subsequently sacrificed 3 months later for analysis of splenic memory $\mathrm{T}$ cell responses (24). Cytokine release in individual splenic cultures was determined at $24 \mathrm{hr}$ (IL-2) or $48 \mathrm{hr}$ (IL-4); mediumalone background values were $<1-2 \mathrm{U} / \mathrm{ml}$ and were subtracted for clarity $(\Delta U / \mathrm{ml})$. (B) Persistence of gene-transferred B cells. Hybridomas were also generated from spleens of tolerized mice by PEG fusion of A20 cells with LPS-activated splenocytes $(48 \mathrm{hr}$, $50 \mu \mathrm{g} / \mathrm{ml}$ LPS). Hybridomas were selected in 1 $\mathrm{mg} / \mathrm{ml} \mathrm{G418}$ and tested for their ability to activate the $9 \mathrm{C} 127 \mathrm{~T}$ cell hybrid as above. Eight representative A20 hybridomas from each recipient (1-3) are shown. may facilitate "tailor-designing" the immune response to a whole antigen by selectively inducing immunity (27) or tolerance to selected immunodominant as well as cryptic epitopes. Furthermore, in contrast to expressing heterologous epitopes in the CDR3 region of Ig $\mathrm{H}$ chains (27), fusion of antigenic sequences at the $\mathrm{N}$ terminus is not limited by size restrictions, and it can thus be adapted for expressing whole autoantigenic proteins such as factor VIII (29), myelin basic protein $(10,11)$, or glutamic acid decarboxylase (9). Delivery of tolerogen as a gene sequence has many theoretical advantages over present tolerance induction protocols, since only the cDNA sequence of the target antigen needs to be known (thus bypassing protein purification strategies). More importantly, since experimentally acquired tolerance eventually wanes, expression and persistence of tolerogen in long-lived or multipotential hematopoietic tissue can potentially modulate a specific immune response permanently.

Another compelling application of genetic tolerogenesis is that an important obstacle to immune elimination of genetically altered cells that is encountered with gene therapy protocols. It has been demonstrated that autologous cells genetically modified with adenoviral and retroviral vectors have resulted in immune recognition of vector-encoded products and subsequent elimination of these transduced cells via both cellular and humoral immunity in immunocompetent recipients (30). Although immunity to low-level expression of viral proteins of first-generation, El-deleted adenovirus will undoubtedly be reduced with further deletion or modification of vectors, rejection of the foreign transgenes expressed by such vectors has been revealed as an even more significant obstacle (31). Our data suggest that tolerogenic pretreatment of immunocompetent recipients with vector-transduced autologous APC expressing viral or foreign transgenes will allow for the prolonged expression and multiple administration of therapeutic transgenes in immunocompetent recipients without need for nonspecific immunosuppression.

Although solid evidence exists for the tolerogenic role of lymphohematopoietic APC in irradiated bone marrow chimeras, our experiments have exploited the potential for mature peripheral B cells to induce efficient peripheral tolerance in unconditioned adults. Our studies have 
for the first time utilized transduced LPS blasts as tolerogenic vehicles, although the mechanism involved for this approach is presently unknown. Previous reports describing tolerance induction via presentation of antigen by resting $B$ cells to naive $\mathrm{T}$ cells has been proposed to stem from the poor expression of costimulatory molecules such as B7-1 and B7-2 (43). Antigen presentation by resting $B$ cells has thus far been useful for the induction of tolerance in naive recipients, but ineffective in primed (22) or allo-MHC-reactive recipients (23) unless anti-gp39 (CD40-ligand) antibodies were simultaneously injected to prevent up-regulation of $B$ cell costimulatory function. Paradoxically, however, as in our experiments, costimulation-competent LPS blasts have also been shown to be efficient tolerogenic APC in vivo for antigen-naive recipients (22) or in vitro for previously activated $\mathrm{T}$ cell clones (24). In parallel studies (44), we describe transgenic mice expressing a peptide-Ig construct specifically in the B cell compartment, which provides even more support on this point. Indeed, while both purified resting or LPS-activated 12-26-IgG transgenic B cells are highly tolerogenic if injected into normal, antigen-naive adults, only LPS-activated transgenic B cells are effective in tolerizing an ongoing immune response for previously primed recipients. These cells, of course, would have the advantage of both $\mathrm{B}$ cell antigen presentation plus secretion of the tolerogenic IgG.

Finally, modification of our protocol for the transduction of proliferating bone marrow-derived dendritic cells with peptide-Ig molecules may also allow for the efficient priming of Th and CTL for viral and tumor peptides and antigens. In summary, genetic transfer of antigenic sequences into peripheral APC, perhaps combined with transgenic expression of immune-modulating molecules such as CD95 (Fas ligand) (45) and CTLA-4 (46), is a very powerful approach for manipulating immune responses associated with autoimmunity, transplantation, and the administration of viral gene therapy vectors.

\section{ACKNOWLEDGMENTS}

The authors wish to acknowledge Dr. Nobu Hozumi for his generous advice and for cell lines, Dr. Tom Briner for reagents, and Drs. R. Michael Blaese, Roland Tisch, Thomas Jensen, and Ray D. Owen for a critique of the manuscript. This is publication \# 14 of the Holland Lab Immunology
Department. This work was supported by N.I.H. grant AI29691 and American Red Cross funds. E.T.Z. was also supported by N.I.H. grants T32GM07356 (MSTP) and T32-AI07285.

\section{REFERENCES}

1. Billingham RE, Brent L, Medawar PB. (1953) Actively acquired tolerance of foreign cells. Nature 172: 603-606.

2. Chiller JM, Habicht GS, Weigle WO. (1970) Cellular sites of immunologic unresponsiveness. Proc. Natl. Acad. Sci. U.S.A. 65: 551-556.

3. Borel Y, Lewis RM, Stollar BD. (1973) Prevention of murine lupus nephritis by carrierdependent induction of immunologic tolerance to denatured DNA. Science 182: 76-78.

4. Ildstad ST, Sachs DH. (1984) Reconstitution with syngeneic plus allogeneic or xenogeneic bone marrow leads to specific acceptance of allografts or xenografts. Nature 307: 168-170.

5. Cobbold SP, Jayasuriya A, Nash A, Prospero TD, Waldmann H. (1984) Therapy with monoclonal antibodies by elimination of $\mathrm{T}$ cell subsets in vivo. Nature 312: 548-551.

6. Roberts JL, Sharrow SO, Singer A. (1990) Clonal deletion and clonal anergy in the thymus induced by cellular elements with different radiation sensitivities. J. Exp. Med. 171: 935-940.

7. Oehen SV, Ohashi PA, Buerki K, Hengartuer H, Zinkernagel RM, Aichele P. (1994) Escape of thymocytes and mature $T$ cells from clonal deletion due to limiting tolerogen expression levels. Cell. Immunol. 158: 342-352.

8. Nemazee D, Bürki K. (1989) Clonal deletion of autoreactive B lymphocytes in bone marrow chimeras. Proc. Natl. Acad. Sci. U.S.A. 86: 8039-8043.

9. Tisch R, Yang X-D, Singer SM, Liblau RS, Fugger L, McDevitt HO. (1993) Immune response to glutamic acid decarboxylase correlates with insulitis in non-obese diabetic mice. Nature 366: 72-75.

10. Higgins PJ, Weiner H. (1988) Suppression of experimental autoimmune encephalomyelitis by oral administration of myelin basic protein and its fragments. J. Immunol. 140: 440-445.

11. Critchfield JM, Racke MK, Zuniger-Pflucker JC, Cannella B, Raine CS, Goverman J, Lenardo MJ. (1994) $\mathrm{T}$ cell deletion in high dose 
antigen dose therapy of autoimmune encephalomyelitis. Science 263: 1139-1143.

12. Ryan JJ, Gness RE, Hathcock KS, Hodes RJ. (1984) Recognition and response to alloantigens in vivo. J. Immunol. 133: 2343-2350.

13. Hori S, Sato S, Kitagawa S, Azuma $T$, Kokudo S, Hamaoka T, Fujiwara H. (1989) Tolerance induction of allo-class II antigenreactive L3T4 and helper T cells and prolonged survival of the corresponding class II $\mathrm{H}-2$ disparate skin graft. J. Immunol. 143: 1447-1452.

14. Madsen JC, Superina RA, Wood KJ, Morris PJ. (1988) Immunological unresponsiveness induced by recipient cells transfected with donor MHC genes. Nature 332: 161-164.

15. Ramsdell F, Lantz T, Fowlkes BJ. (1989) A non-deletional mechanism of thymic self tolerance. Science 246: 1038-1041.

16. Roberts JL, Sharrow SO, Singer A. (1990) Clonal deletion and clonal anergy in the thymus induced by cellular elements with different radiation sensitivities. J. Exp. Med. 332: 161-164.

17. Gao E-K, Lo D, Sprent J. (1990) Strong T-cell tolerance in parent/Fl bone marrow chimeras prepared with supralethal irradiation: Evidence for clonal deletion and anergy. $J$. Exp. Med. 171: 1101-1121.

18. Sachs DH, Bodine DH, Moulton DA, Pearson DS, Nienhuis AW, Sykes M. (1993) Tolerance induction using autologous bone marrow modified with an allogeneic class I MHC gene. Transplant. Proc. 25: 348-349.

19. Sutkowski N, Kuo M-L, Varela-Echavarria A, Dougherty JP, Ron Y. (1994) A murine model for B-lymphocyte somatic cell gene therapy. Proc. Natl. Acad. Sci. U.S.A. 91: 88758879.

20. Webb S, Morris C, Sprent J. (1990) Extrathymic tolerance of mature $\mathrm{T}$ cells: Clonal elimination as a consequence of immunity. Cell 63: 1249-1256.

21. Eynon EE, Parker DC. (1992) Small B cells as antigen-presenting cells in the induction of tolerance to soluble protein antigens. J. Exp. Med. 175: 131-138.

22. Fuchs EJ, Matzinger P. (1992) B cells turn off virgin but not memory $\mathrm{T}$ cells. Science 258: 1156-1159.

23. Buhlmann JE, Foy TM, Aruffo A, Cerassi KM, Ledbetter JA, Green WR, Xu JC, Shultz LD, Roopesian D, Flavell RA, Fast L, Noelle RJ, Durie FH. (1995) In the absence of a
CD40 signal, B cells are tolerogenic. Immunity 2: $645-653$.

24. Gilbert KM, Weigle WO. (1994) Tolerogenicity of resting and activated B cells. J. Exp. Med. 179: 249-258.

25. Soloway P, Fish S, Passmore H, Gefter $M$, Coffee R, Manser T. (1991) Regulation of the immune response to peptide antigens: Differential induction of immediate-type hypersensitivity and T-cell proliferation due to changes in either peptide structure or major histocompatibility complex haplotype. $J$. Exp. Med. 174: 847-858.

26. Lai M-Z, Ross D, Guillet JG, Briner T, Gefter M, Smith JA. (1987) T lymphocyte response to bacteriophage $\lambda$ repressor $\mathrm{cl}$ protein. $\mathrm{J}$. Immunol. 139: 3973-3980.

27. Zaghouani $H$, Steinman $R$, Nonacs $R$, Shah H, Gerhard W, Bona C. (1993) Presentation of a viral $\mathrm{T}$-cell epitope expressed in the CDR3 region of a self immunoglobulin molecule. Science 259: 224-227.

28. Zambidis ET, Scott DW. (1996) Epitope-specific tolerance induction with an engineered immunoglobulin. Proc. Natl. Acad. Sci. U.S.A. 93: 5019-5024.

29. Allain JP, Frommel D. (1976) Patterns of immune response to Factor VIII in hemophilia A. Blood 47: 973-982.

30. Yang Y, Li Q, Ertl HC, Wilson JM. (1995) Cellular and humoral immune responses to viral antigens create barriers to lung-directed gene therapy with recombinant adenoviruses. J. Virol. 69: 2004-2015.

31. Tripathy SK, Black HB, Goldwasser E, Leiden JM. (1996) Immune response to transgene-encoded proteins limits the stability of gene expression after injection of replication-defective adenovirus vectors. Nat. Med. 2: 545-550.

32. Kang J, Wither J, Hozumi N. (1990) Proc. Natl. Acad. Sci. U.S.A. Long-term expression of a T-cell receptor $\beta$-chain in mice reconstituted with retrovirus-infected hematopoietic stem cells. 87: 9803-9087.

33. Keller G, Paige C, Gilboa E, Wagner EF. (1985) Expression of a foreign gene in myeloid and lymphoid cells derived from multipotent haematopoietic precursors. Nature 318: 149-154.

34. Dick JE, Magli MC, Huszar D, Phillips RA, Bernstein A. (1985) Introduction of a selectable gene into primitive stem cells capable of long-term reconstitution of the hemopoietic system of $\mathrm{W} / \mathrm{W}^{\mathrm{v}}$ mice. Cell 42: 71-79. 
35. Bodine DM, Karlsson S, Nienhuis AW. (1989) Combination of interleukins 3 and 6 preserves stem cell function in culture and enhances retrovirus-mediated gene transfer into hematopoietic stem cells. Proc. Natl. Acad. Sci. U.S.A. 86: 8897-8901.

36. Grosschedl R, Weaver D, Baltimore D, Costantini F. (1984) Introduction of a $\mu$-immunoglobulin gene into the mouse germ line: Specific expression in lymphoid cells and synthesis of functional antibody. Cell 38: 647-658.

37. Weiss S, Bogen B. (1991) MHC class II-restricted presentation of intracellular antigen. Cell 64: 767-776.

38. Bikoff E, Birshtein BK. (1986) T cell clones specific for IgG2a of the a allotype: Direct evidence for presentation of endogenous antigen. J. Immunol. 137:28-34.

39. Yurin VL, Rudensky AY, Mazel SM, Blechman JM. (1989) Immunoglobulin-specific $\mathrm{T}-\mathrm{B}$ cell interaction. II. $\mathrm{T}$ cell clones recognize the processed form of B cells' own surface immunoglobulin in the context of the major histocompatibility complex class II molecule. Eur. J. Immunol. 19:1685-1691.

40. Dorshkind K, Keller GM, Phillips RA, Miller RG, Bosma GC, O'Toole M, Bosma MJ. (1984) Functional status of cells from lymphoid and myeloid tissues in mice with se- vere combined immunodeficiency disease. J. Immunol. 132: 1804-1808.

41. Sprent J, Schaefer M, Hurd M, Suth CD, Ron Y. (1991) Mature murine B and T cells transferred to SCID mice can survive indefinitely and many maintain a virgin phenotype. $J$. Exp. Med. 174: 717-728.

42. Ally BA, Hawley TS, McKall-Faienza KJ, Kundig TM, Oehen SU, Pircher H, Hawley RG, Ohashi PS. (1995) Prevention of autoimmune disease by retroviral-mediated gene therapy. J. Immunol. 155: 5404-5408.

43. Hathcock KS, Laszlo G, Pucillo C, Linsley $P$, Hodes RJ. (1994) Comparative analysis of B7-1 and B7-2 costimulatory ligands: Expression and function. J. Exp. Med. 180: 631-640.

44. Zambidis E, Barth R, Scott DW. (1997) Both resting and activated $B$ lymphocyte expressing engineered peptide-immunoglobulin molecules serve as highly efficient tolerogenic vehicles in immunocompetent adult recipients. J. Immunol. 158: 2174 .

45. Crispe IN. (1994) Fatal interactions: Fas-induced apoptosis of mature $\mathrm{T}$ cells. Immunity 1: 347-349.

46. Walunas TL, Lenschow DJ, Bakker CY, Linsley PS, Freeman GJ, Green JM, Thompson CB, Bluestone JA. (1994) CTLA-4 can function as a negative regulator of $\mathrm{T}$ cell activation. Immunity 1: 405-413.

Communicated by R. Bucala. Accepted December 3, 1996. 